\title{
Digital technology in the humanities and public life in the context of justice
}

\author{
Nurmagomed Ismailov ${ }^{1, *}$, Eleonora Barkova², and Olga Buzskaya² \\ ${ }^{1}$ Research Institute of History, Economics and Law, Moscow, Russian Federation \\ ${ }^{2}$ Russian Economic University named after G.V. Plekhanov, Moscow, Russian Federation
}

\begin{abstract}
The article explores some methodological issues and the role of digital technologies in the humanities, education system, and public life. The relevance of the research topic is confirmed by the rapid development of digital resources and technologies in public life, including humanities and education. The positive role of digital technologies for the development of humanities and education is emphasized; they are characterized by interdisciplinarity and open up new possibilities for research. It is argued that the process of digitalization is a reflection of the new historical realities of social life, including science and education, a reflection of the new needs of society in the research environment. And materialistic understanding of the phenomena of social life as the most important method of research, comprehension, and evaluation of social processes is used as the main method of research. It is argued that digital technologies in the humanities and education have serious negative consequences. This manifests itself in a potential decrease in intellectual activity, analytical abilities, and physical development of a person. Digital technologies are capable of taking a person into another reality, disrupting the process of traditional socialization, live communication. Such processes have a negative impact on his personal development, which contradicts the criterion of justice and social progress, which are expressed in the comprehensive development of the individual. It is argued that even the most advanced digital technology cannot replace the moral and psychological moments of live teacher-student communication.
\end{abstract}

\section{Introduction}

Modern society is characterized by the rapid development of digital resources and technologies in many of its areas. This process affects many areas of society, including science and education. One cannot ignore the fact that this process has an enormous impact on the humanities, social sciences and philosophy as well. New technologies are dramatically changing the modern world, are present in research processes, and expand the very boundaries of research in the humanities and the whole system of education and science. The use of digital technologies in the humanities automatically transforms the latter into digital ones.

Under present conditions, society has to reckon that the humanities are now characterized to some extent as digital. Indeed, this does not exclude the fact that individual researchers,

\footnotetext{
*Corresponding author: nur.is.filosof@ rambler.ru
} 
for various reasons, may remain outside the process of using digital technologies. The mathematical methods adopted by the humanities, of course, significantly open up new possibilities for research in the humanities and, in some respects, direct this research towards interdisciplinarity.

However, this does not mean that the ultimate goals and objectives of the research and education system change. Yes, new means are used to achieve research goals in the social sciences, philosophy, science, and education. But the ultimate goal remains the same, which we see in the formation of a highly moral, fully developed, and educated person.

One correction should be made here. The ultimate goals of science and education remain the same. But it is safe to say that preliminary goals in using digital technologies in the humanities can, and will, change. These objectives are now outlined as identifying the role and outcomes of digital technologies in the research process, their implementation in the teaching and educational process.

The process of introducing digital technologies and resources into humanities research has led to the emergence of an interdisciplinary field that is now commonly referred to as digital humanities or digital humanistic (Digital Humanities). E.Yu. Zhuravleva points out that the plurality of terms meaning the intersection of information technology "and the humanities are related to historical, political, disciplinary and educational contexts" $[1, \mathrm{p}$. 92].

\section{Study methodology}

As a methodological basis of the research, we use the principle of development, considering the problem of humanities, social sciences, and education in change and development, the principle of historicism, considering the dynamics of problems, having a place in the humanities and all system of science and education in interrelation with concrete events of the given epoch.

We also use a comprehensive approach, taking into account the results of research on the problem of different humanities, social sciences; we try to consider the problem from a systemic-philosophical position, from the position of axiological approach.

The axiological approach allows us to reveal people's attitudes to education and spirituality through the prism of their values in a given era, through the prism of the concept of morality and moral evaluations. In this regard, it seems very important to assess the development of digital technologies in the humanities and social sciences in the context of social justice, in the context of improvement or, on the contrary, degradation of human abilities and personal qualities. The main criterion of justice is the comprehensive development of the individual and the development of society as a whole.

In our study of the role and results of digital technologies in the humanities, we assume that this process reflects the new realities, a reflection in the research environment of the new needs of society. We use the materialistic understanding of history as the most important method of research and evaluation of social processes.

Here, we can also speak of a pronounced interdisciplinary character of digital humanities since the methods used in the humanities are complemented by the methods of informatics, computer science methods. Here, the role of information, which is now becoming an important object of study for both social and natural sciences, for example, is emphasized.

In this context, we should take into account the fact that information as a concept and phenomenon of social life has a different interpretation by representatives of different sciences. In this respect, it seems to make sense to rely, first of all, on the philosophical interpretation of the concept of information. Since, as we know, it is the philosophy that contains the results, conclusions, and achievements of the various sciences in a strippeddown form. 
Interdisciplinary methods also provide perspective for research in the humanities. Traditional, historically established methods of scientific knowledge can now be supplemented by new sociological methods and tools, such as sociological surveys, questionnaires, collection of public opinion data, etc. Digital technologies allow us not only to preserve and expand the historical and cultural heritage but also to develop tools for analyzing the data obtained by scientists.

\section{Results of the study}

As a result of the study of digitalization of the humanities, the whole system of education, and public life, we can conclude that this process is, to some extent, a natural stage in the development of society. There is no doubt that the development of technology of all kinds is a constant process. In this regard, the development of digital technology is one of the stages and means of improving the productive forces of society. And humanities, social sciences, philosophy should not fall out of this process. It is digitalization that helps the humanities and society as a whole to retain and digest so much information in an increasingly complex world.

Digitalization of the humanities leads to well-known digital tools, which help scientists, specialists to conduct their research. Electronic forms of research data, machine processing of this data allow the general public to benefit from the information obtained. Y.D. Prudenko and D.Yu. Kuzmina note that in modern conditions, "the development of science, engineering and often art is proportional to the development of digital technologies, which not only influence the formation of all these spheres separately but also contribute to their fusion" [2, p. 18]. Studies are emerging that point to the possible emergence of electronic Superintelligence in the not too distant future of humankind and, in this regard, try to predict the future of humans [3].

Even without a request from researchers, information systems lead to so-called big data, which can automatically accumulate information. Not surprisingly, people's use of various social media, mobile phones, and bank cards, of course, leads to so-called electronic footprints. These traces, in turn, can be used by other people, e.g., scientists, as well as special services of various kinds, to investigate them. Of course, research into these data can be conducted both with good intentions and to record people's worldviews, particularly political positions, to monitor their future behavior.

The digitalization of humanities, education, and public life, for all its positive aspects and higher productivity, poses certain problems for the good functioning of people and society if the processes of digitalization are viewed from the perspective of justice and freedom.

Firstly, a person who, by justice, should be free (of course, we are talking about a fair measure of freedom) is now forced to obey programs and algorithms, the creation of which he personally has nothing to do with. A man receives a certain degree of comfort and convenience in exchange for restricting his individual freedom [4, p. 199-200]. In this respect, the notions of justice, freedom, and responsibility are given new meaning. If this problem is considered in the context of globalization and globalism, it may be thought that the world elite, through digitalization, is trying to make people more obedient so that they will resemble soulless robots.

Digitalization of public life can be observed in many areas: economics, finance, science, education, etc. For example, digital money is increasingly replacing cash, which not everyone wants to give up. Because in this case, certain categories of people would have to give up their habitual way of life. However, the new realities of life are forcing people to adapt to the digital world. As noted by Academician V.L. Makarov, life in the digital world contributes to the change of many things, including ethical perceptions, social norms [see 5, p. 147]. 
Digitalization even leads, to a certain extent, to a change in the concept of identity. You could say that the concept of "digital identity" is emerging. Whereas digital technology used to be just an auxiliary tool, for example, in certain studies, it is now increasingly becoming a determining factor in human behavior. "However, not everything can be expressed in the language of numbers. Fortunately, human beings cannot be fully measured by numbers alone" [6].

Digital slavery, which is no longer just a conventional notion but to some extent a reality of life, cannot but contradict the principle of justice and legitimate individual freedom.

It should also be pointed out that under total control of all social life, a person loses their privacy and the so-called digital totalitarian system is possible. The digitalization of humanities, education, and all social life necessarily lead to a situation where the life of individuals and social groups becomes "transparent" for those interested in this "transparency", also for certain services. This natural process of the emergence of "transparency" of citizens' private lives is also facilitated by the so-called electronic traces, which have already been mentioned above. Stakeholders, services, social forces can know almost everything about a person thanks to their indestructible "digital footprint". These traces become the domain of the aforementioned big data.

It may very well be that a person has not yet conceived of certain future actions, but the relevant competent authorities already foresee them. Neighbors or acquaintances no longer have to report these possible actions of a person who is not exactly what the authorities want. A person's world view, including his or her political, legal, moral values, as well as his or her possible behavior, is known to the authorities and relevant services.

They are known for digital technology and the general public. Knowing the preferences, a person may be attracted to various interest groups, sports, and cultural groups, religious sects, extremist organizations. "Digital footprints" can give away almost every characteristic of a person's identity to all concerned. As you know, digital technology allows you to capture and record people's voices, even with digital devices turned off, for example, if the laptop or smartphone camera is not covered. It is also possible to note the fact pointed out by I.A. Antoshchuk and V.Yu. Ledeneva that social networks and institutions have a certain role in the process of transnational mobility [7, p. 109-110]. It seems that "digital footprints" play a role in this phenomenon as well.

In recent years, individual researchers have increasingly pointed to the dangers of a digital totalitarian society. It is noted that the global digital cave may serve as a kind of prototype of possible totalitarian society. If we address the question of the greatest danger posed by the digitalization process, it is seen in the creation of conditions for the powerful development of totalitarianism, according to V.V. Mironov [see 8].

\section{Discussion of results}

Of course, digital research does not inspire all scientists to the same degree. And some specialists are skeptical about this new direction, not considering it necessary to recognize digital humanities as an independent field of scientific research. And we must admit that there is some truth in such views. One cannot but agree that the new direction is merely using new technologies in already existing areas of scientific knowledge.

However, we can also agree that the development of specific research principles, methods, and scientific tools allows us to refer digital humanities to a relatively independent field of research. Digital technology can dramatically increase the productivity of traditional humanities research. In this regard, it is advisable to popularize digital technologies to outline the most promising directions in their improvement. K.R. Bayanov believes that knowledge of the future "opens up the practical possibility of controlling influences on the vector of the historical process" [9, p. 41]. Bayanov also rightly believes that foreseeing social phenomena 
of the future using digital technologies does not cancel the metaphysical vision of the coming course of social processes. In social forecasting, digital technology can only play a supporting role [10].

Digital technologies in the humanities significantly reduce time in the research process, make it possible to compare and summarize research results much faster, and obtain, though not always, the necessary information through various search engines. It is no longer necessary to travel to larger cities to work in the library to find the literature you need. In this respect, the researcher's work becomes easier and less costly.

However, this sometimes remote work can lead the researcher to become intellectually inactive. He stops gleaning the necessary information independently, reflecting properly on the process, and comparing results. This is now mainly handled by an internet search engine. In this plan, a person's thinking and analytical functions are not always involved, leading to a weakening of these abilities.

The more developed digital technologies are, the more a person, as a rule, goes to the virtual world, to another reality, which disrupts the process of his/her traditional socialization, live communication. And this already has a significant negative impact on his/her personal development, which contradicts the criterion of social justice and social progress, which we see in the comprehensive development of the individual [11, p. 43]. Even the most advanced and perfect digital technologies can never replace live communication between a teacher and a student, respectively, the atmosphere of a traditional classroom, moral and psychological moments of live communication between teachers and students.

It is also unfortunate that digital technologies in any sciences and the education system have serious negative effects on people's physical development. Here we can talk about the weak development of the musculo-muscular system of a person, his fine motor skills, a sharp deterioration of vision, etc.

With the best intentions of the creators of digital technology, this process can and probably already is leading to total control by the authorities, special services, and relevant organizations over people, their thoughts, political and moral beliefs, their behavior, and their entire lives. This last factor, considered in the context of notions of justice, human rights, and freedoms, to a large extent overrides many positive aspects of the digitalization of humanities, education, and human life activities.

\section{Conclusion}

This study of the process of digitalization of the humanities allows us to reveal, to a certain extent, the role and consequences of this process for the development of the humanities and the whole social life. It can be concluded that the digital humanities, based on interdisciplinarity, are, to some extent, a continuation and addition of the historically established humanities. Russian researcher A.Yu. Volodin states that "the digital transition in the humanities can be considered to have taken place" [12, p. 5]. There is reason to believe that digitalization, in general, is a natural consequence of the development of society and a historical necessity. The process of digitalization of humanities, education, and all social life, among other things, requires its obligatory further investigation in the context of notions of justice, freedom, and social progress.

\section{References}

1. E.Yu. Zhuravleva, Questions of Philosophy 5, 91 (2011)

2. Ya.D. Prudenko, D.Yu. Kuzmina, International Journal of Cultural Research 3(8), 17 (2012) 
3. A. D. Korolev, A.A. Zenkin, Overmind, or Battlefield - Human Body, 328 (2018)

4. N.O. Ismailov, Bulletin of Dagestan State University 5, 199 (2014)

5. G.M. Birzhenyuk, Sociological researches 1, 146 (2018)

6. Philosophy of the digital world, PhilosophyStorm.org >filosofiya-tsifrovogo-mira

7. I.A. Antoshchuk, V.Yu. Ledeneva, Sociological Research 2, 108 (2019)

8. Philosophy of the digital world, PhilosophyStorm.org >filosofiya-tsifrovogo-mira

9. K.R. Bayanov, Bulletin of the Moscow State Regional University, Series: Philosophical Sciences 1, 32 (2010)

10. K.R. Bayanov, Social Sciences 2, 116 (2010)

11. N.O. Ismailov, Justice: Conceptual Foundations and Actual Problems (2016)

12. A.Yu. Volodin, Bulletin of Perm University, Series "History" 3(26), 5 (2014) 